feed restriction...) did not give any positive results, we applied to injection of hormone such as P.M.S. and H.C.G. The results of this study show the favourable effect of hormonal treatments : systematic insemination of the sows before $100 \mathrm{~kg}$ (at age of 7 months) on day 4 and 5 after injection of 400 units of PMS and 200 units of HCG led to obtention of 26 p. Ioo pregnant sows and a mean number of foetuses exceeding 9 at 30 days of gestation. These results seem to be poor as compared to those obtained by SCHILLING in 1972 , but they have the advantage of supplying the minimum rate of conception to be expected in practise.

\title{
Fertility and prolifieacy of sows inseminated with frozen semen : efiect of the moment of insemination
}

\author{
M. PAQUigNON, C. DELAHAYE, J. BUSSIERE*, M. COUROT* \\ Institut Technique du Porc, \\ 149, rue de Bercy, \\ 75579 Paris Cedex 19 \\ Société Sanders, Centre expérimental de Sourches, \\ 72480 Bernay-en-Champagne \\ * Laboratoire de Physiologie de la Reproduction, \\ Centre de Recherches de Tours, I. N. R. A., \\ B. P. 1, Nouzilly, 37380 Monnaie
}

Various experiments were made in order to determine the optimum moment for insemination in the case of heat detection once per day by means of a teasor boar and in order to estimate fertility and prolificacy results of the sows checked for oestrus by the farmer. The best results (65-70 p. Ioo pregnant sows) were obtained when inseminations with frozen semen were realized 24 hours after the presumed onset of heats. Prolificacy was slightly lower than that obtained after insemination with fresh semen. 